\title{
Application of Dose Area Product (DAP) to Estimate Entrance Surface Dose (ESD) in Pediatric Chest X-Rays
}

\author{
Roya Davoodi ${ }^{1}$, Mohammad-Reza Eydian ${ }^{2}$, Hessein Karampour ${ }^{1}$, Mahdi Nassarpour ${ }^{1}$, Reza Rezazadeh-Farokh ${ }^{1}$, \\ Asma Maraei ${ }^{1} \&$ Mohammad Chavideh $^{2}$ \\ ${ }^{1}$ Department of Medical Engineering, School of Technical and Engineering, Dezful Branch, Islamic Azad \\ University, Dezful, Iran \\ ${ }^{2}$ Student Research Committee, Dezful University of Medical Sciences, Dezful, Iran \\ Correspondence: Mohammad Chavideh, Student Research Committee, Dezful University of Medical Sciences, \\ Dezful, 6461665145, Iran. Tel: 98-9016-740-097. E-mail: arianurse77@yahoo.com
}

Received: July 5, 2020; Accepted: August 1, 2020; Published: August 17, 2020

The research is financed by Payam-Noor University of Mashhad, Iran.

\begin{abstract}
Introduction: Given the high radiation tissue sensitivity of pediatric patients, it is necessary to monitor their received dose to optimize radiation protection. The first aim of this study was to evaluate the entrance surface dose (ESD) in pediatric patients undergoing a chest X-ray at the main hospital of Dezful, Iran. The second aim was to compare our results with the established dose reference levels (DRLs).

Materials and Methods: The studied population included 204 pediatric patients less than 15 years who were referred to as chest X-ray. A calibrated dose area product meter (DAP-meter) with permanent installation on the $\mathrm{X}$-ray unit was used to radiation dose measurements. For each patient, the demographic data, exposure parameters and the dose read by DAP-meter were recorded and ESD was calculated using a standard mathematical formula.

Results: The average value of ESD was $119 \mu \mathrm{Gy}$ in patients less than 15 years. This value was 51.3, 122.3, 131.5 and $171.2 \mu \mathrm{Gy}$ for the age groups for less than 1 year, 1 to 5 years, 5 to 10 years and 10 to 15 years, respectively. A statistically significant difference was seen between ESD values in different age groups $(\mathrm{P}<0.001)$, whereas no statistical difference was seen between ESD values in girls and boys $(\mathrm{P}=0.993)$.
\end{abstract}

Conclusion: Pediatric patients in hospital investigated (except age group less than 1 year) are subjected to unnecessary radiation exposure, especially due to the use of non-optimize X-ray protocols.

Keywords: Dose area product, Chest X-ray, Pediatric, Patient, Radiation, ESD

\section{Introduction}

Although the discovery of X-rays by Wilhelm Conrad Rontgen in 1895 has revolutionized medical care, their use involves some potential health risks to an individual patient undergoing diagnostic and therapeutic procedures[1]. This risk has established to inversely proportion with patients age, suggests high radiation tissue sensitivity of pediatric patients. Several studies have reported that pediatrics to be as much as 10 times more susceptible to radiation induce carcinogenesis than adults [2-4]. Therefore, it is necessary to monitor their received radiation dose, especially for frequent $\mathrm{X}$-ray examinations to radiation protection optimization.

Chest X-ray is one of the frequent X-ray examinations requests by pediatricians for pediatric patients [4]. Even though the radiation dose associated with a singular chest X-ray is low, but due to wide frequency, radiation dose optimization should be considered [4]. Evidence showed that there is a wide variation in the amount of radiation dose received by pediatric patients for the same type of X-ray examinations such as chest X-rays [5-7]. These variations result in some patients receives more radiation doses than needed. Accordingly, the international commission on radiological protection (ICRP) has recommended diagnostic reference levels (DRLs) as a guide to protect patients from undue radiation exposure [8]. DRL determine through the third quartile of the average entrance surface dose (ESD) distribution [9]. ESD which is defined as the absorbed dose at the entrance surface of the tissue has been identified as the best indicator for monitor patients' dose during X-ray examinations [10,11]. It can measure directly using thermoluminescent dosimeters (TLD) or indirectly by a mathematical formula based 
on tube output at free-air or dose area product meter (DAP-meter) $[10,12,13]$. There are rarely studies on radiation dose measurement during pediatric chest X-rays in Iran. Bahreyni Toossi et al. [5] reported an ESD value of 76.3 $\mu$ Gy and a DRL value of $88 \mu$ Gy for neonatal chest X-rays in Mashhad. Similarly, Faghihi et al [14] reported an ESD value of $56.6 \mu \mathrm{Gy}$ for neonatal chest X-rays in Shiraz. This study aimed to evaluate the ESD in pediatric patients undergoing chest X-rays using DAP-meter at the large teaching hospital of Dezful-Iran.

\section{Method}

This study was performed during a period of 6-months in the radiology center of the teaching hospital of Dezful University of Medical Sciences (Dr. Ganjavian). Exposures were performed using a single digital radiography unit (VARIAN X-ray system, UAS) with total filtration of 3-mm aluminum and a focal spot of 1-mm ${ }^{2}$. This unit has a fixed anti-scatter radiation grid that allows all exposure to be performed using the grid. Before the study, approval was provided from the university ethic committee to proceed. Moreover, informed consent was obtained from the parents. The studied population included 204 pediatric patients who were referred to as clinically indicated chest $\mathrm{X}$-ray. Patients were considered eligible for inclusion if their age was less than 15 years, have anteroposterior (AP) or posteroanterior (PA) view of the chest X-ray on their request sheet and their parents have signed informed consent form. The emergency patients and patients with lateral view of the chest X-ray were excluded from the study. Following the literatures $[6,12,15]$, patients were divided into four age groups of less than 1 year, 1 to 5 years, 5 to 10 years and 10 to 15 years. For each patient, the demographic data and exposure parameters were measured and recorded. A calibrated dose area product meter (DAP-meter) with permanent installation on the Xray unit was used to radiation dose measurements (Figure 1). DAP is defined as the absorbed dose multiplied by the area of tissue irradiated which reflects dose in the radiation field together with area of tissue irradiated. ESD was calculated using the following mathematical formula [16].

$$
\mathrm{ESD}=\left(\frac{\mathrm{DAP}}{A(\mathrm{FID})}\right) \cdot\left(\frac{\mathrm{FID}}{\mathrm{FSD}}\right)^{2} \cdot \mathrm{BSF}(A(\mathrm{FID}))\left(\frac{\mu_{\mathrm{en}}}{\rho}\right)_{\text {Air }}^{\text {Tissue }}
$$

Where, A (FID) is the area of radiation field on the patient skin $\left(\mathrm{cm}^{2}\right)$, DAP: dose measured by DAP-meter $\left(\mathrm{mGy} \times \mathrm{cm}^{2}\right)$, FSD: X-ray focus to skin distance (m), FFD: X-ray focus to film distance (m), BSF: Backscatter Factor for the given A (FID) $[17,18]$ and ${ }^{\left(\mu_{\mathrm{en}} / \rho\right)_{\text {Air }}^{\text {Tissue }}}$ tissue-to-air mass-energy absorption coefficient ratio [19, 20].

Data were entered into Microsoft Excel (Microsoft Inc., Redmond, WA) and statistical analysis was performed using SPSS software (IBM, Armonk, New York). The one-way analysis of variance (ANOVA) was used to measure and compare ESD values in different age groups. Moreover, an independent paired t-test was used to compare ESD values in the boy and girl subjects.

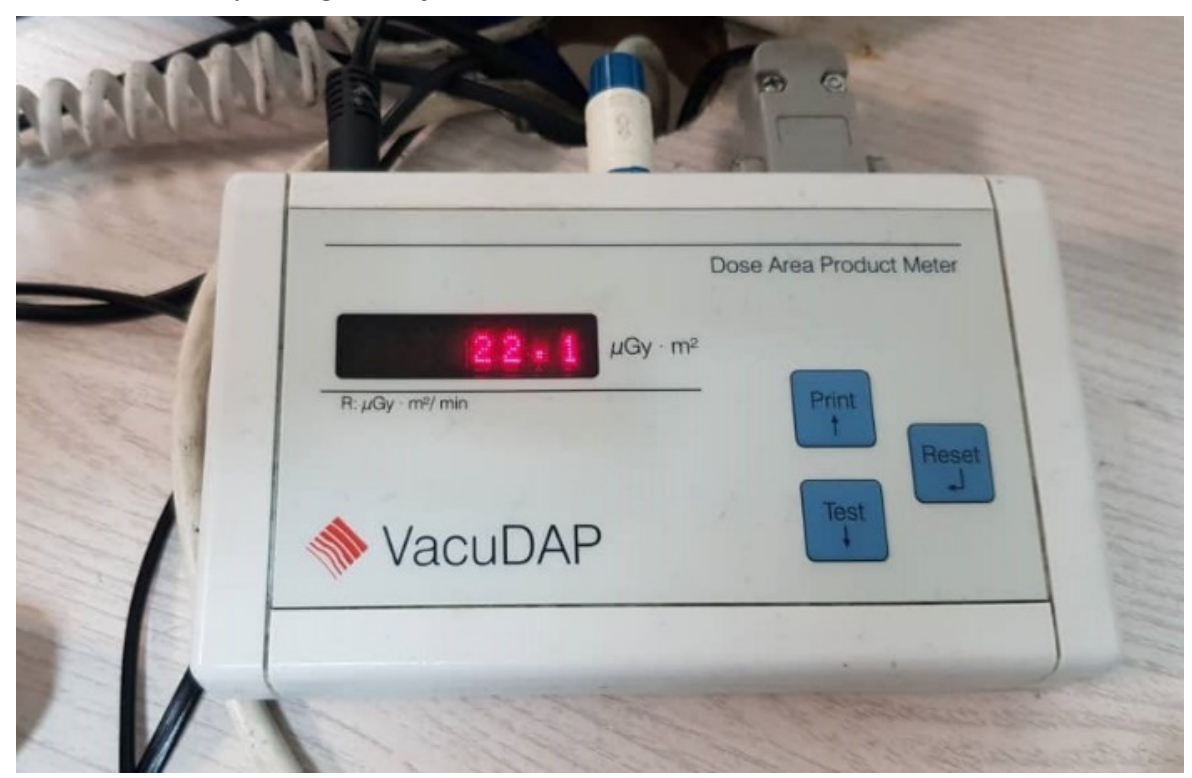

Figure 1. Dose area product meter (DAP-meter) with permanent installation on the X-ray unit 


\section{Results}

Of 204 pediatric patients enrolled in the study, 81 (39.7\%) of whom were girls and 123 (60.3\%) were boys. The characteristic of patients and exposure parameters and calculated ESD are presented in Table 1. The average value of ESD was $119 \mu \mathrm{Gy}$ in patients less than 15 years. This value was 51.3, 122.3, 131.5 and $171.2 \mu \mathrm{Gy}$ for the age groups less than 1 year, 1 to 5 years, 5 to 10 years and 10 to 15 years, respectively (Figure 2). There was a statistical significant difference between ESD value in different age groups $(\mathrm{P}<0.001)$. Increasing patients' age was resulted in increasing ESD value. There was a significant correlation between applied current-time-product (mAs) and tube potential $(\mathrm{kVp})$ with ESD values, whereas no meaningful correlation was found for patients' $\operatorname{sex}(\mathrm{P}=0.993)$.

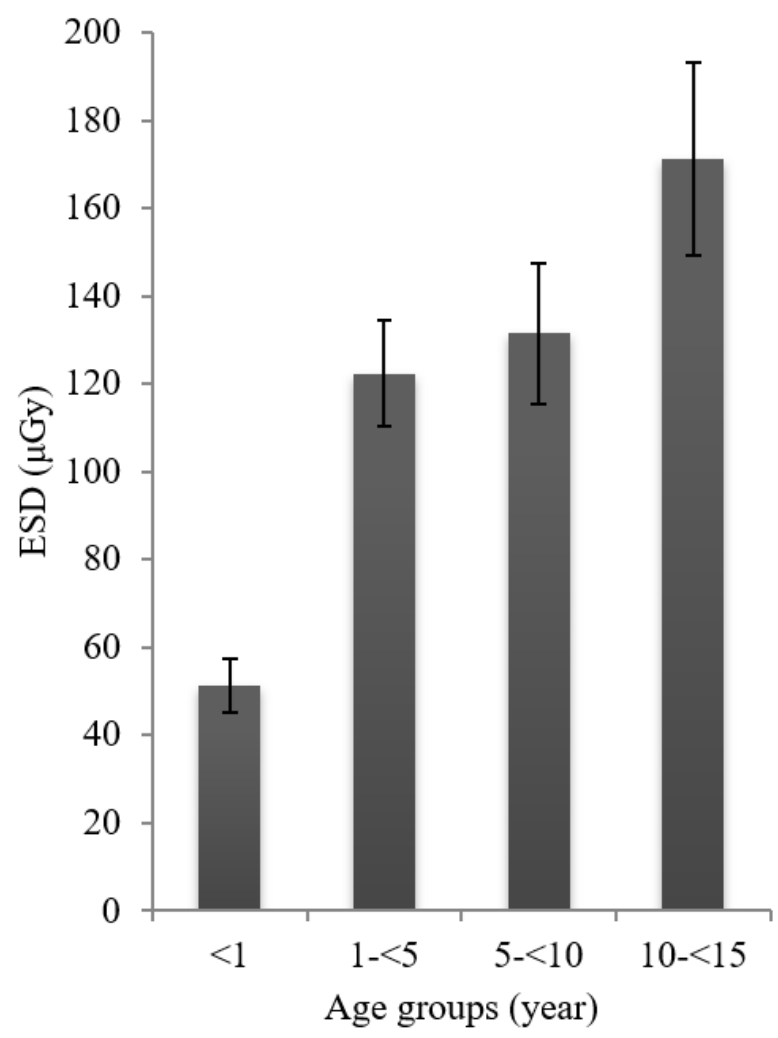

Figure 2. Average ESD in pediatric patients undergoing chest $\mathrm{x}$-ray as a function of patient age

Table 1. Characteristic of patients and exposure parameters during pediatric chest $\mathrm{x}$-rays

\begin{tabular}{|c|c|c|}
\hline Variable & $\begin{array}{l}\begin{array}{l}\text { Average } \\
\text { (range) }\end{array} \\
\end{array}$ & Standard deviation \\
\hline Weight $(\mathrm{kg})$ & $\begin{array}{l}17.87 \\
(2.50-50)\end{array}$ & 11.80 \\
\hline Height $(\mathrm{cm})$ & $\begin{array}{l}83.25 \\
(12-140)\end{array}$ & 20.51 \\
\hline $\mathrm{A}\left(\mathrm{cm}^{2}\right)$ & $\begin{array}{l}24.71 \\
(18-30)\end{array}$ & 4.73 \\
\hline FFD $(\mathrm{cm})$ & $\begin{array}{l}118.87 \\
(35-150)\end{array}$ & 24.29 \\
\hline $\mathrm{FSD}(\mathrm{cm})$ & $\begin{array}{l}104.2 \\
(18-123)\end{array}$ & 18.4 \\
\hline $\mathrm{kVp}$ & $67.59(50-90)$ & 9.08 \\
\hline mAs & $\begin{array}{l}8.75 \\
(4-20)\end{array}$ & 3.55 \\
\hline DAP (mGy.cm²) & $\begin{array}{l}33.94 \\
(4.8-87)\end{array}$ & 19.86 \\
\hline
\end{tabular}


Abraviations: A. area of radiation field on patients skin, FFD. Focus to film distance, FSD. Focus to skin distance, DAP. Dose area product

\section{Discussion}

Patient radiation dose measurement is crucial to optimize radiological protection in X-ray centers. This study provides useful information about the radiation dose received by pediatric patients undergoing a chest X-ray at our hospital. It can be used for comparing patients' dose with the established DRL values so that patients do not receive unnecessary radiation exposure than needed. According to our results, the average ESD value for patients less than 1 year, 1 to 5 year, 5 to 10 year and 10 to 15 year were $51.3,122.3,131.5$ and $171.2 \mu$ Gy which are consistent with reported by Atalabi et al. for pediatric chest X-rays, respectively [6]. The ESD value of $51.3 \mu \mathrm{Gy}$ measured in this study for the age group less than 1 year is consistent with 56.6 and $52 \mu \mathrm{Gy}$ reported by Faghihi et al [14] and Smans et al. [21] for neonatal chest X-rays, whereas, it was lower than $76.3 \mu \mathrm{Gy}$ reported by Bahreyni Toossi et al. [5]. Both agreement and discordance were present between our study and the study performed by Ademola et al. [15] on pediatric chest X-rays. They reported an ESD value of 111 and $159 \mu \mathrm{Gy}$ for the age group of 1 to 5 years and 5 to 10 years which is similar to 122.3 and $131.5 \mu$ Gy obtained in our study. However, they reported an ESD value of $620 \mu \mathrm{Gy}$ for 10 to $15 y$ years patients which are substantially higher than $171.2 \mu \mathrm{Gy}$ obtained in our study. Similarly, our results are inconsistent with ESD value of 182, 172, 340 and $587 \mu$ Gy reported by Zewdu et al for patients less than 1 year, 1 to 5 years, 5 to 10 years and 10 to 15 year during chest X-rays [12]. These variations could be explained by variation in the applied FSD and exposure parameters ( $\mathrm{kVp}$ and $\mathrm{mAs})$, patient habitus, use or not use of anti-scatter grid and X-ray unites used in these studies. We found no significant correlation between patients' sex and weight with ESD values, whereas, a significant correlation was seen for the applied $\mathrm{kVp}$ and $\mathrm{mAs}$. These results are consistent with the literature [6].

The DRL value of 50,70 and $120 \mu \mathrm{Gy}$ has been recommended for a 1 year, 5 years and 10 -years pediatric patient undergoing chest X-ray, respectively [7]. Our results are consistent with the recommended DRL value of $50 \mu \mathrm{Gy}$ for the age group of less than 1 year. However, for the age group 1 to 5 years and 5 to 10 years, the ESD value of 122.3 and $131.5 \mu \mathrm{Gy}$ measured in this study are higher than recommended DRL values of 70 and $120 \mu \mathrm{Gy}$ which refers to non-optimization of radiological protection for these age groups. The patient dose is particularly influenced by variation in the applied exposure parameters [12]. The European Commission (EC) has recommended tube potential $(\mathrm{kVp})$ of 60 to 80 for pediatric patients less than 1 year and 100 to 120 for 5 years and higher [22]. The use of tube potential less than $60 \mathrm{kVp}$ has also been discouraged. This advice comes from this fact that appropriate combining the use of high $\mathrm{kVp}$ and low $\mathrm{mAs}$ would result in reducing patient dose [5]. In this study, the radiographers were used of 60 to $65 \mathrm{kVp}$ for patients less than 1 year, 63 to 70 for 1 to 5 years, 65 to 70 for 5 to 10 years and 65 to $75 \mathrm{kVp}$ for 10 to 15 -years patients. Generally speaking, an inappropriate exposure parameter KVp used for pediatric chest X-rays can explain all of these elevation in ESD (except for the age group less than 1 year). Such concern has been reported in the works of literature [12,15]. This study indicated that 1 to 15 -years pediatric patients in the hospital investigated is subjected to unnecessary radiation exposure, especially due to the use of non-optimize X-ray protocols. We recommend provision and adherence to a written departmental radiation safety protocol to protect pediatric patients from undue exposure to radiation. The protocol used for pediatric chest X-rays should undergo a Quality Control (QC) program to ensure low dose patient as well as high image quality.

\section{Acknowledgments}

This study was extracted from the master's thesis of the first author and a research project approved by the PayamNoor University of Mashhad.

\section{References}

[1] Ward, R., Carroll, W. D., Cunningham, P., Ho, S-A, Jones, M., Lenney, W., et al. (2017). Radiation dose from common radiological investigations and cumulative exposure in children with cystic fibrosis: an observational study from a single UK centre. BMJ Open, 7(8), e017548. https://doi.org/10.1136/bmjopen-2017-017548

[2] Curtis JR. (2010). Computed tomography shielding methods: A literature review. Radiologic Technology, 81(5), 428-36.

[3] Hohl, C., Wildberger, J., Süß, C., Thomas, C., Mühlenbruch, G., Schmidt, T., et al. (2006). Radiation dose reduction to breast and thyroid during MDCT: effectiveness of an in-plane bismuth shield. Acta Radiologica, 47(6), 562-7. https://doi.org/10.1080/02841850600702150

[4] Kostova-Lefterova, D., Taseva, D., Hristova-Popova, J., \& Vassileva, J. (2015). Optimisation of paediatric chest radiography. Radiation Protection Dosimetry, 165(1-4), 231-4. https://doi.org/10.1093/rpd/ncv119 
[5] Toossi, M. T. B., \& Malekzadeh, M. (2012). Radiation dose to newborns in neonatal intensive care units. Iranian Journal of Radiology, 9(3), 145-9. https://doi.org/10.5812/iranjradiol.8065

[6] Atalabi, O. M., Bidemil, A., Adekanmi, A. J., \& Samuel, O. A. (2013). Entrance surface dose from pediatric diagnostic x-ray examinations in a developing world setting: are we'ALARA principle'compliant? British Journal of Medicine and Medical Research, 3(4), 2288-98. https://doi.org/10.9734/BJMMR/2013/4119

[7] Kim, B. H., Do, K. H., Goo, H. W., Yang, D. H., Oh, S. Y., Kim, H. J., et al. (2012). National survey of radiation doses of pediatric chest radiography in Korea: analysis of the factors affecting radiation doses. Korean Journal of Radiology, 13(5), 610-7. https://doi.org/10.3348/kjr.2012.13.5.610

[8] Nikupaavo, U., Kaasalainen, T., Reijonen, V., Ahonen, S. M., \& Kortesniemi, M. (2015). Lens dose in routine head CT: comparison of different optimization methods with anthropomorphic phantoms. American Journal of Roentgenology, 204(1), 117-23. https://doi.org/10.2214/AJR.14.12763

[9] Freitas, M. B., \& Yoshimura, E. M. (2009). Diagnostic reference levels for the most frequent radiological examinations carried out in Brazil. Revista Panamericana de Salud Pública, 25(2), 95-104. https://doi.org/10.1590/S1020-49892009000200001

[10] Jornet, N., Muñoz, J., Martin-Viera, J., Jurado, D., Pallerol, R., Gultresa, J., et al. Determination of entrance surface dose in standard explorations in radiodiagnostic. Retrieved January 2019, from https://pdfs.semanticscholar.org/f406/79f5061c9bf368feb0768bf68f3dce621f2d.pdf

[11] Ofori, K., Gordon, S. W., Akrobortu, E., Ampene, A. A., \& Darko, E. O. (2014). Estimation of adult patient doses for selected X-ray diagnostic examinations. Journal of Radiation Research and Applied Sciences, 7(4), 459-62. https://doi.org/10.1016/j.jrras.2014.08.003

[12] Zewdu, M., Kadir, E., \& Berhane, M. (2017). Assessment of pediatrics radiation dose from routine x-ray examination at Jimma University Hospital, Southwest Ethiopia. Ethiopian Journal of Health Sciences, 27(5), 481-90. https://doi.org/10.4314/ejhs.v27i5.6

[13] Gholami, M., Maziar, A., Khosravi, H., Ebrahimzadeh, F., \& Mayahi, S. (2015). Diagnostic reference levels (DRLs) for routine X-ray examinations in Lorestan province, Iran. International Journal of Radiation Research, 13(1), 85-90.

[14] Faghihi, R., Mehdizadeh, S., Sina, S., Alizadeh, F. N., Zeinali, B., Kamyab, G. R., et al. (2011). Radiation dose to neonates undergoing X-ray imaging in special care baby units in Iran. Radiation protection dosimetry. 150(1), 55-9. https://doi.org/10.1093/rpd/ncr373

[15] Ademola, A., Obed, R., Adejumobi, C., Abodunrin, O., Alabi, O., \& Oladapo, M. (2013). Assessment of Entrance Skin Dose in routine x-ray examinations of chest, skull, abdomen and pelvis of children in five selected hospitals in Nigeria. IOSR Journal of Applied Physics. 5(2), 47-50. https://doi.org/10.9790/48610524750

[16] Kisielewicz, K., Truszkiewicz, A., Wach, S., \& Wasilewska-Radwańska, M. (2011). Evaluation of dose area product vs. patient dose in diagnostic X-ray units. Physica Medica, 27(2), 117-20. https://doi.org/10.1016/j.ejmp.2010.07.001

[17] Hart, D., Jones, D., \& Wall B. (1994). Estimation of effective dose in diagnostic radiology from entrance surface dose and dose-area product measurements. National Radiological Protection Board, 71(849), 994-5. https://doi.org/10.1259/bjr.71.849.10195022

[18] Hart, D., Jones, D., \& Wall B. (1996). Coefficients for estimating effective doses from paediatric x-ray examinations: National Radiological Protection Board Oxon.

[19] Martin, C. (1995). Measurement of patient entrance surface dose rates for fluoroscopic x-ray units. Physics in Medicine \& Biology, 40(5), 823-34. https://doi.org/10.1088/0031-9155/40/5/008

[20] McParland, B. (1998). Entrance skin dose estimates derived from dose-area product measurements in interventional radiological procedures. The British Journal of Radiology, 71(852), 1288-95. https://doi.org/10.1259/bjr.71.852.10319003

[21] Smans K, Struelens L, Smet M, Bosmans H, Vanhavere F. (2008). Patient dose in neonatal units. Radiation Protection Dosimetry, 131(1), 143-7. https://doi.org/10.1093/rpd/ncn237

[22] European Union. European Commission. (1996). Directorate-General XII-Science R, Development. European guidelines on quality criteria for diagnostic radiographic images in paediatrics: Office for Official Publications of the European Communities. 


\section{Copyrights}

Copyright for this article is retained by the author(s), with first publication rights granted to the journal.

This is an open-access article distributed under the terms and conditions of the Creative Commons Attribution license (http://creativecommons.org/licenses/by/4.0/). 